\title{
Properties of Strontium Copper Oxide Films Prepared by Radio Frequency Reactive Magnetron Sputtering with Different Oxygen Partial Pressures
}

\author{
Jui-wen Liu*1, Shih-chin Lee*2 and Chih-hao Yang*1 \\ Department of Materials Science and Engineering, National Cheng Kung University, Tainan, Taiwan, R. O. China
}

Transparent conductive strontium copper oxide (SCO) films were grown on glass substrates by radio frequency magnetron sputtering technique at room temperature with different oxygen partial pressures. Structural, electrical and optical properties of these films were studied. Grazing incidence angle x-ray diffraction (GIAXRD) analysis showed that $\mathrm{SrCu}_{2} \mathrm{O}_{2}$ structure was achieved when oxygen partial pressure was raised above $2.0 \times 10^{-1} \mathrm{~Pa}$. Both carrier density and resistivity of the film varied with oxygen partial pressure. The carrier density and resistivity of the film prepared with $4.0 \times 10^{-1} \mathrm{~Pa}$ of oxygen pressure were $2.89 \times 10^{21} \mathrm{~cm}^{-3}$ and $6.64 \times 10^{-2} \Omega \cdot \mathrm{cm}$, respectively. The carrier mobility was $0.092 \mathrm{~cm}^{2} \mathrm{~V}^{-1} \mathrm{~s}^{-1}$ and the Hall coefficient measured at room temperature indicated that the conduction is p-type. The optical transmittance in the visible range at $550 \mathrm{~nm}$ was $29 \% \sim 41 \%$. [doi:10.2320/matertrans.MER2007108]

(Received May 7, 2007; Accepted July 9, 2007; Published September 5, 2007)

Keywords: transparent conductive oxide, thin films, electrical properties, p-type semiconductor

\section{Introduction}

Transparent conductive oxides (TCO) are widely applied as transparent electrodes in flat panel displays, solar cells and coatings for anti-static electricity shielding because of their good optical and electrical properties. N-type TCO films, such as zinc oxide $(\mathrm{ZnO})$, indium tin oxide (ITO) and tin oxide doped $\left(\mathrm{SnO}_{2}: \mathrm{F}\right)^{1)}$ have been extensively studied. These metallic oxide-based materials have high electrical conductivity and good optical transparency in visible spectrum. Unfortunately, there have been only a few studies on transparent semiconductor devices have been done due to the lack of available p-type TCO materials. ${ }^{2-4)}$

According to the review article by Hiroshi Kawazoe et $a l .,{ }^{5)}$ the difficulties in designing a material with positive holes that are not localized on oxygen atoms has resulted in the lack of p-type transparent oxides. This is due, at least in part, to the fact that holes localized on oxygen atoms are hard to migrate within the crystal lattice. A method called "chemical modulation of valence bound" (CMVB) has been proposed to reduce the localization effect of holes. ${ }^{5)}$ Using this method, extended valence band can be achieved by introducing the covalence into the metal-oxygen bonding. The chemical formula of p-type oxides with the preferred delafossite structure is $\mathrm{AMO}_{2}$. Many oxides have demonstrated their p-type conductivity, such as $\mathrm{CuAlO}_{2},{ }^{6-9)}$ $\mathrm{CuInO}_{2},{ }^{10)} \mathrm{CuGaO}_{2}{ }^{11)}$ and $\mathrm{CuScO}_{2} .{ }^{12)}$ Delafossite thin films demonstrate good optical and electrical properties, yet high deposition temperature $(973.15 \mathrm{~K})$ becomes the major limit to their application for fabricating multilayered devices.

In comparison with delafossites, strontium copper oxide (SCO) can be deposited at a temperature as low as $623.15 \mathrm{~K}$ by pulse laser deposition technique (PLD). ${ }^{13)}$ This low deposition temperature makes strontium copper oxide a potential candidate for making multilayered devices with other thin films that are easily subjected to thermal damage.

In addition to the PLD process, strontium copper oxide

\footnotetext{
${ }^{* 1}$ Graduate Student, National Cheng Kung University, R.O.C

${ }^{* 2}$ Corresponding author, E-mail: n5890105@mail.ncku.edu.tw
}

thin films have also been successfully fabricated by the solution deposition technique. ${ }^{14)}$ In this paper, the structural, electrical and optical properties of SCO films deposited in different oxygen partial pressure by the extensively used sputtering method are studied.

\section{Experimental Details}

SCO films were deposited by a radio frequency (RF) magnetron sputtering system on microscope carrier glasses with optical refractive index of 1.5. Big pieces of glass were cut into $1 \times 1 \mathrm{~cm}^{2}$ substrates for follow-up deposition processes. Deposition rate decreased from $55 \mathrm{~nm} / \mathrm{hr}$ to $20.5 \mathrm{~nm} / \mathrm{hr}$ as oxygen partial pressure increased from 0 (pure Ar) to $4 \times 10^{-1} \mathrm{~Pa}$. All substrates were ultrasonically cleaned in an acetone and alcohol solution, and de-ionized water was used to remove all the organic contaminants. The 99.9\% pure SCO target was purchased from GUV Team International Co., Ltd. The X-ray diffraction pattern showed that the target was polycrystallized $\mathrm{SrCuO}_{2}$. Ar and $\mathrm{O}_{2}$ used in this experiment were $99.999 \%$ ultra high purity gases. Before the sputtering process, the background pressure of the vacuum chamber was reduced to below $1.5 \times 10^{-4} \mathrm{~Pa}$ and the deposition process was performed at $4.0 \times 10^{-1} \mathrm{~Pa}$ of total pressure. There were three sputtering targets in our sputtering system and the target diameter was $76.2 \mathrm{~mm}$. The substrate rotated at a speed of $10 \mathrm{rpm}$ during the depositing process. The actual growth time of the films was only onequarter of the overall period of sputtering. The substrate was kept at room temperature during sputtering process. Film thickness was measured using an alpha-step surface profiler (TENCOR MA-1450). The films were typically $100 \mathrm{~nm}$-thick as measured by surface profiler. The structure of various processing parameters was measured using a grazing incident angle X-ray diffractormeter (GIAXRD). A four-point probe (Model RT-70, NAPSON, Japan) was used to measure the sheet resistivity of the films. The carrier density and mobility of the films were measured using the Hall effect in Van der Pauw method. All values of film thickness and the electrical characteristics are average data from measuring different 


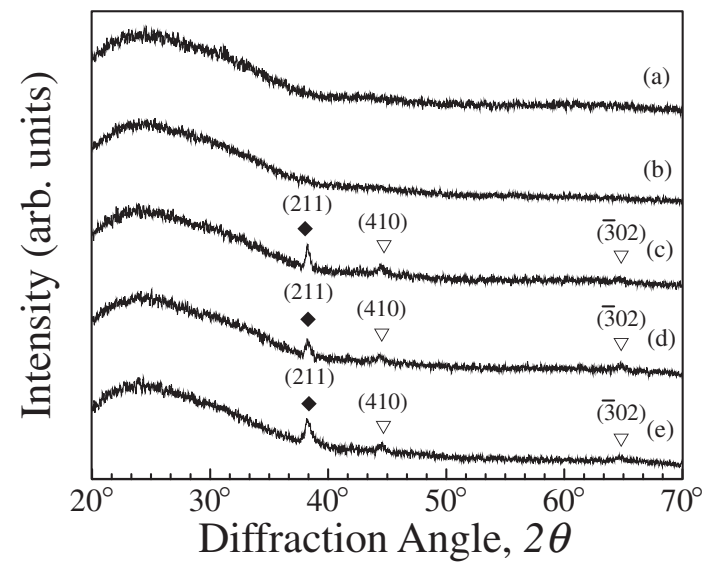

Fig. 1 GIAXRD patterns of SCO films deposited at $100 \mathrm{~W}$ of target power, room temperature and different oxygen partial pressures: (a) pure $\mathrm{Ar}$, $4.0 \times 10^{-1} \mathrm{~Pa}$, (b) $\mathrm{O}_{2}, 1.0 \times 10^{-1} \mathrm{~Pa}$, (c) $\mathrm{O}_{2}, 2.0 \times 10^{-1} \mathrm{~Pa}$, (d) $\mathrm{O}_{2}$, $3.0 \times 10^{-1} \mathrm{~Pa}$, and (e) $\mathrm{O}_{2}, 4.0 \times 10^{-1} \mathrm{~Pa}$. The marked peaks in " $\bullet$ " and " $\nabla$ " correspond to $\mathrm{SrCu}_{2} \mathrm{O}_{2}$ and $\mathrm{SrCuO}_{3}$ respectively.

positions on the sample. Optical transmittance and absorbance were measured using an ultraviolet/visible/near infrared spectrophotometer (UV/VIS/NIR spectrophotometer, Hitachi U4001) in a wavelength range of $200 \sim 1100 \mathrm{~nm}$. The transmission percentages were calculated from the measured percentage transmission of the corresponding bare substrates.

\section{Results and Discussion}

According to previous research, the properties of transparent conductive oxides and oxygen partial pressure are highly correlated to each other. ${ }^{15,16)}$ For this study, deposition processes were performed varying the oxygen partial pressure, i.e. 0 (totally argon), $1.0 \times 10^{-1}, 2.0 \times 10^{-1}, 3.0 \times$ $10^{-1}$ and $4.0 \times 10^{-1} \mathrm{~Pa}$. Figure 1 shows the GIAXRD patterns $(2 \theta)$ as a function of oxygen partial pressure of deposition parameters for SCO films grown on glass substrates at room temperature. These patterns indicate that the films deposited with oxygen partial pressure below $1.0 \times 10^{-1} \mathrm{~Pa}$ are amorphous. As the oxygen partial pressure reaches $2.0 \times 10^{-1} \mathrm{~Pa}$, a peak corresponding to the (211) plane of crystallized $\mathrm{SrCu}_{2} \mathrm{O}_{2}$ (JCPDS relative card \#381178 ) is observed in the profile. The other peaks marked with " $\nabla$ " in the profile are $\mathrm{SrCuO}_{3}$ (JCPDS relative card \#860052). Even though there could have been additional oxides in the films, such as $\mathrm{CuO}, \mathrm{Cu}_{2} \mathrm{O}, \mathrm{Sr}_{0.74} \mathrm{CuO}_{2},{ }^{16)}$ this could not be verified in these patterns since no related peaks were revealed.

Figure 2 shows the resistivity of the films plotted as a function of oxygen partial pressure during the deposition processes, except the film deposited in a pure argon atmosphere since that was out of measurable range. Since the film deposited in argon atmosphere has such poor electrical properties it received no further discussion. This figure shows clearly that electrical conductivity was improved when oxygen was introduced in the deposition atmosphere, and the resistivity decreased rapidly with increasing oxygen partial pressure. The lowest resistivity of SCO films was

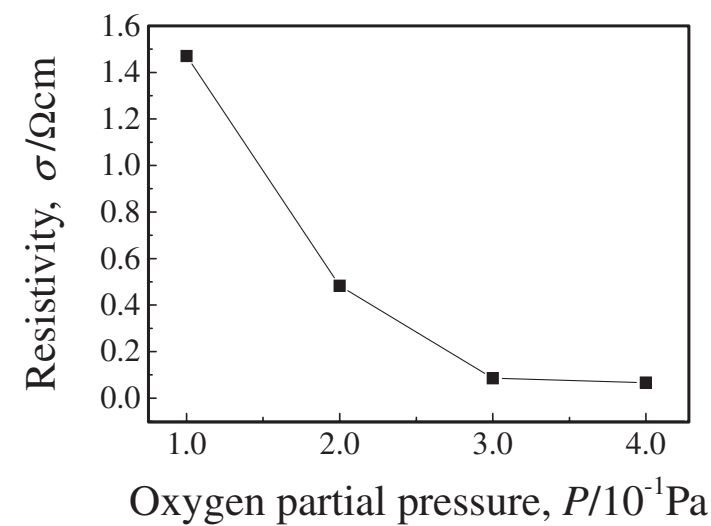

Fig. 2 Resistivity of SCO films deposited at $100 \mathrm{~W}$ of target power, room temperature and different oxygen partial pressures.

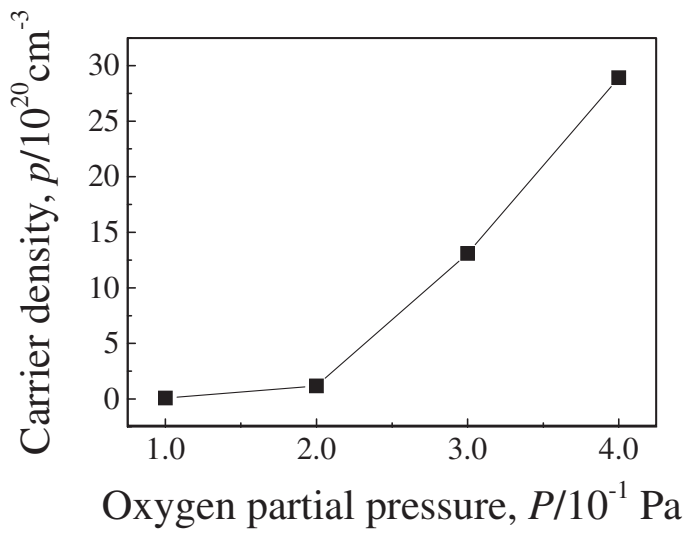

Fig. 3 Carrier density of SCO films deposited at $100 \mathrm{~W}$ of target power, room temperature and different oxygen partial pressures.

$6.64 \times 10^{-2} \Omega \cdot \mathrm{cm}$ at $4.0 \times 10^{-1} \mathrm{~Pa}$ of oxygen partial pressure.

Figure 3 shows the carrier density of SCO films deposited at $100 \mathrm{~W}$ of target power and room temperature with different oxygen partial pressure. The results show that the carrier density of SCO films increases with increasing oxygen partial pressure. According to Banerjee et al., ${ }^{15)}$ excess oxygen provides carriers in the films, that is, positive holes in p-type conductive oxides. Figure 4 shows the carrier mobility of films measured at room temperature. This figure illustrates with higher carrier density, the carrier mobility will be less due to increased scattering of carriers. Another reason for the decrease in mobility is the scattering effect of grain boundary when oxygen partial pressure is raised above $2.0 \times 10^{-1}$ Pa. ${ }^{17,18)}$ It is well known that peaks in a diffraction pattern will broaden as the grain size decreases, indicating that there are more grain boundaries in samples with broader peaks. The calculated full widths at half maximum (FWHM) of (211) plane of SCO films are listed in Table 1. These results show that the FWHM increased with increasing oxygen partial pressure. With higher oxygen partial pressure, there is less kinetic energy of sputtered particles or atoms for the crystallization process, and so smaller grain size is formed.

The transmission spectra of films deposited with different oxygen pressure and $100 \mathrm{~W}$ of target power at room temperature were shown in Fig. 5. According to the 


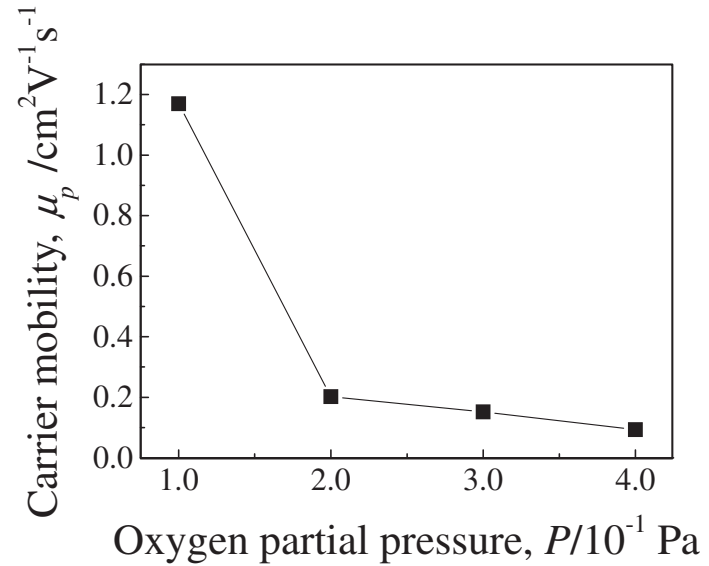

Fig. 4 Carrier mobility of SCO films deposited at $100 \mathrm{~W}$ of target power, room temperature and different oxygen partial pressures.

Table 1 Calculated FWHM of (211) plane for SCO films deposited at $100 \mathrm{~W}$ of target power, room temperature and different oxygen partial pressures.

\begin{tabular}{cc}
\hline $\begin{array}{c}\text { Oxygen partial pressure, } \\
P / \mathrm{Pa}\end{array}$ & $\begin{array}{c}\text { Full widths at half maximum, } \\
F W H M / \text { degree }\end{array}$ \\
\hline $1.0 \times 10^{-1}$ & None \\
$2.0 \times 10^{-1}$ & 0.373 \\
$3.0 \times 10^{-1}$ & 0.458 \\
$4.0 \times 10^{-1}$ & 0.647 \\
\hline
\end{tabular}

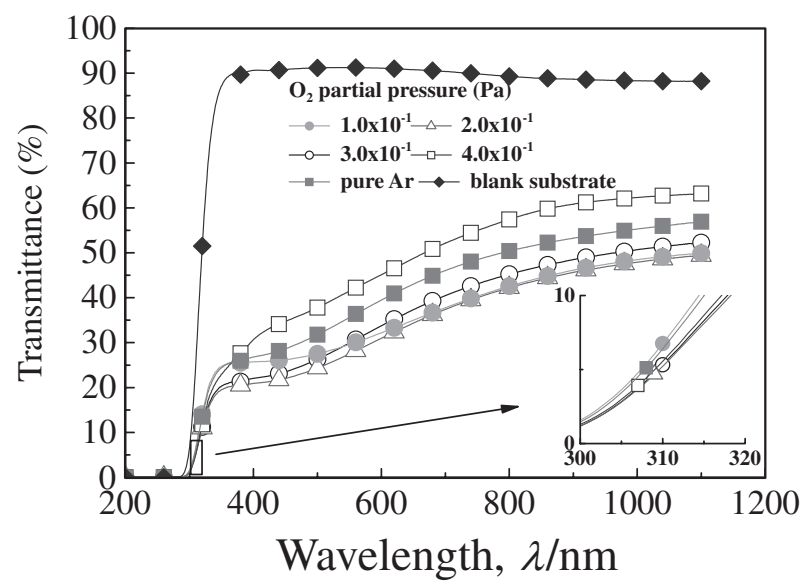

Fig. 5 Optical transmission spectra of SCO thin films deposited at $100 \mathrm{~W}$ of target power, room temperature and different oxygen partial pressures.

comparison of the GIAXRD results with the transmission spectra, we propose that these films could be divided into two groups. The first group of films, deposited with oxygen partial pressure lower than $1.0 \times 10^{-1} \mathrm{~Pa}$, formed amorphous structures. The second group of films, deposited with oxygen partial pressure above $2.0 \times 10^{-1} \mathrm{~Pa}$, was crystallized $\mathrm{SrCu}_{2} \mathrm{O}_{2}$ and $\mathrm{SrCuO}_{3}$.

It is generally agreed that the absorption coefficient $\alpha$ can be related to the photon energy $h v$ by

$$
(\alpha h v)^{2}=A\left(h v-E_{g}\right)
$$

where $\mathrm{A}$ is a constant and $\mathrm{E}_{\mathrm{g}}$ is the optical energy gap.

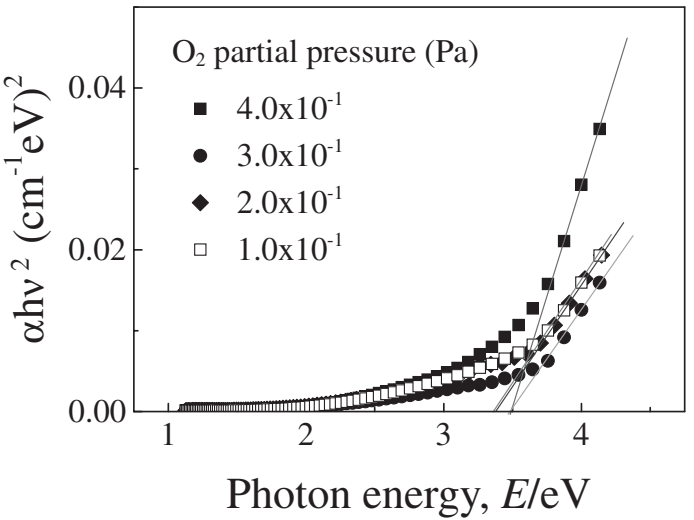

Fig. 6 Band gap energy of SCO films deposited at $100 \mathrm{~W}$ of target power, room temperature and different oxygen partial pressures.

Figure 6 shows a plot of $(\alpha h v)^{2}$ vs. photon energy $(h v)$ for SCO film deposited at room temperature with different oxygen partial pressure. The optical band gap $\left(E_{g}\right)$ of the film was obtained from the figure, from which the linear portion is extrapolated to where $\alpha h v$ is zero. ${ }^{19)}$ The evaluated Eg is $3.3 \sim 3.5 \mathrm{eV}$, which is similar to the value of $3.3 \mathrm{eV}$ obtained by Nie et al. ${ }^{20)}$ and Hosono et al. ${ }^{21)}$ The Burstein-Moss shift caused by increased carrier density of the films can be observed in both groups. ${ }^{22,23)}$

The Hall coefficient measurement was performed to identify the major conduction type of the deposited films. The Hall coefficient measured at $298 \mathrm{~K}$ was +0.154 for the film obtained at $4.0 \times 10^{-1} \mathrm{~Pa}$ oxygen and $100 \mathrm{~W}$ of target power. This result clearly shows that the conduction is $\mathrm{p}$ type.

\section{Conclusion}

Strontium copper oxide films were prepared on glass substrates by reactive RF magnetron sputtering technique with different oxygen partial pressure at room temperature. These films exhibited improved resistivity with increasing oxygen partial pressure. GIAXRD analysis revealed that $\mathrm{SrCu}_{2} \mathrm{O}_{2}$ was formed in the deposited films when oxygen partial pressure was raised above $2.0 \times 10^{-1} \mathrm{~Pa}$. The highest optical transmission of SCO films deposited with $4.0 \times$ $10^{-1} \mathrm{~Pa}$ of oxygen and $100 \mathrm{~W}$ of target power was observed above $41.5 \%$ at a wavelength of $550 \mathrm{~nm}$. The Hall carrier density also increased with increasing oxygen partial pressure. The p-type conduction of the films was confirmed and the Hall coefficient measured at $298 \mathrm{~K}$ was in the range of 28.5 to 0.154 .

\section{REFERENCES}

1) C. G. Granqvist and A. Hultaker: Thin Solid Films 411 (2002) 1-5.

2) H. Ohta, K. Kawamura, M. Orita, M. Hirano, N. Sarukura and H. Hosono: Appl. Phys. Lett. 77 (2000) 475-477.

3) H. Yanagi, K. Ueda, H. Ohta, M. Orita, M. Hirano and H. Hosono: Solid State Commun. 121 (2001) 15-17.

4) H. Ohta, M. Orita, M. Hirano and H. Hosono: J. App. Phys. 89 (2001) 5720-5725.

5) K. Hiroshi, Y. Hiroshi, U. Kazushige and H. Hideo: MRS Bulletin 25 (2000) 28-36. 
6) H. Kawazoe, M. Yasukawa, H. Hyodo, M. Kurita, H. Yanagi and H. Hosono: Nature 389 (1997) 939-942.

7) H. Yanagi, S. Inoue, K. Ueda, H. Kawazoe, H. Hosono and N. Hamada: J. App. Phys. 88 (2000) 4159-4163.

8) B. J. Ingram, T. O. Mason, R. Asahi, K. T. Park and A. J. Freeman: Phys. Rev. B 64 (2001) 155114.

9) Y. Wang, H. Gong, F. Zhu, L. Liu, L. Huang and A. C. H. Huan: Mater Sci. Eng., B 85 (2001) 131-134.

10) H. Yanagi, T. Hase, S. Ibuki, K. Ueda and H. Hosono: Appl. Phys. Lett. 78 (2001) 1583-1585.

11) K. Ueda, T. Hase, H. Yanagi, H. Kawazoe, H. Hosono, H. Ohta, M. Orita and M. Hirano: J. App. Phys. 89 (2001) 1790-1793.

12) N. Duan, A. W. Sleight, M. K. Jayaraj and J. Tate: Appl. Phys. Lett. 77 (2000) 1325-1326.

13) A. Kudo, H. Yanagi, H. Hosono and H. Kawazoe: Appl. Phys. Lett. 73 (1998) 220-222.
14) D. Ginley, B. Roy, A. Ode, C. Warmsingh, Y. Yoshida, P. Parilla, C. Teplin, T. Kaydanova, A. Miedaner and C. Curtis: Thin Solid Films 445 (2003) 193-198

15) A. N. Banerjee, C. K. Ghosh and K. K. Chattopadhyay: Sol. Energy Mater. Sol. Cells 89 (2005) 75-83.

16) E. Bobeico, F. Varsano, C. Minarini and F. Roca: Thin Solid Films 444 (2003) 70-74.

17) H. C. Lee: Appl. Surf. Sci. 252 (2006) 2647-2656.

18) H. C. Lee and O. O. Park: Vacuum 75 (2004) 275-282.

19) M. T. Bhatti, A. M. Rana and A. F. Khan: Mater. Chem. Phys. 84 (2004) 126-130.

20) X. Nie, S. H. Wei and S. B. Zhang: Phys. Rev. B 65 (2002) 075111.

21) H. Ohta, M. Orita, M. Hirano, I. Yagi, K. Ueda and H. Hosono: J. App. Phys. 91 (2002) 3074-3078.

22) E. Burstein: Phys. Rev. 93 (1954) 632-633.

23) T. S. Moss: Proc. Phys. Soc. London, Sect. B 67 (1954) 775-782. 